Supplement of Saf. Nucl. Waste Disposal, 1, 57-58, 2021

https://doi.org/10.5194/sand-1-57-2021-supplement

(c) Author(s) 2021. CC BY 4.0 License.

(c) (i)

Supplement of

\title{
Investigation of Surface Exploration Programs for Hydrological, Hydrogeological and Hydrogeochemical Issues in the Site Selection Procedure
}

\author{
Kirsten Haneke et al. \\ Correspondence to: Kirsten Haneke (k.haneke@brenk.com)
}

The copyright of individual parts of the supplement might differ from the article licence. 


\section{Project "übErStand":}

\section{Investigation of surface exploration programmes}

for hydrological, hydrogeological and hydrogeochemical issues in the site selection procedure

BASE-project: FKZ 4717F01201
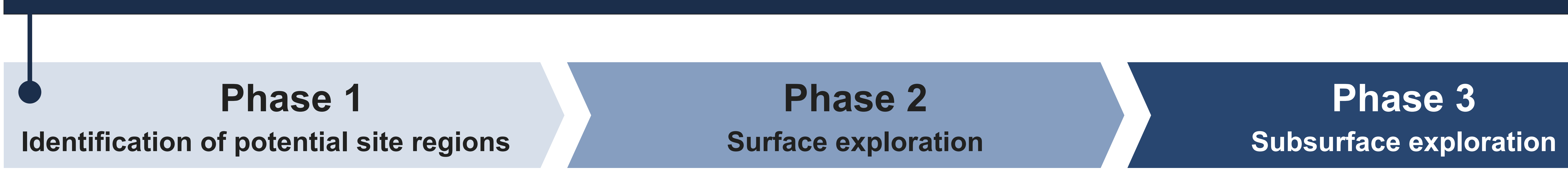

\section{Step 1}

Derivation of relevant parameters for surface exploration methods from the StandAG

$\checkmark$ Systematic presentation and explanation of the specific criteria and requirements related to hydrology, hydrogeology or hydrochemistry from the StandAG.

$\checkmark$ Derivation of relevant parameters for determination by surface exploration methods.

$\checkmark$ Comprehensive compilation of parameters related to hydrology, hydrogeology and hydrochemistry for surface exploration of the three host rocks.

Fluid motion and
transport relevant rock prop
sorption
$\mathrm{E}_{\mathrm{h}}$
$\mathrm{pH}$
major and trace elements
ionic strength
viscosity
density
isotopic ratio
conductivity/salinity
colloids

Hydrochemistry

\section{Geohydraulic methods}

\section{Surface geophysical exploration methods}

\section{Borehole geophysical exploration methods}

Laboratory tests, field tests

\section{Step 2}

Description of exploration methods used to determine identified parameters

$\checkmark$ Elaboration of the relevant and suitable surface exploration methods according to the current state of the art in science and technology.

$\checkmark$ Description of ranges, reproducibilities, detection limits, advantages and disadvantages and possible combinations with other methods.

$\checkmark$ Consideration of the three different host rocks.

$\checkmark$ Allocation of the "most suitable" exporation methods to all relevant parameters for surface exploration programs at siting regions (generic).

\section{Step 3}

Classification and derivation of an orientation framework

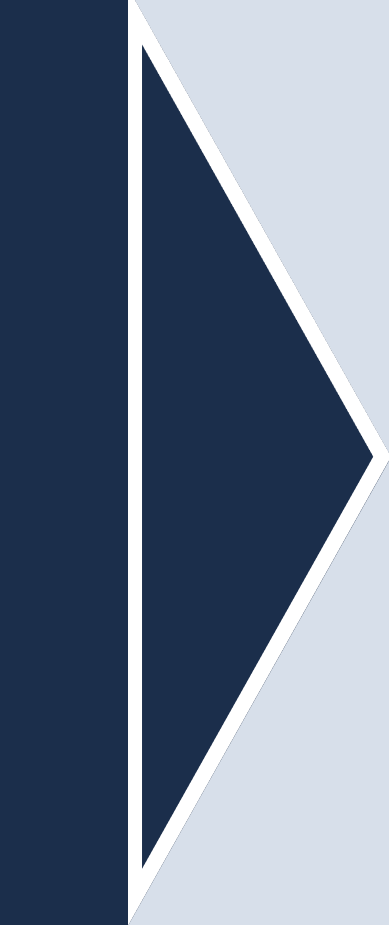

Requirements for complete documentation and quality assurance.

Criteria for evaluating the quality and quantity of measured values and the results.

$\checkmark$ Factors influencing the criteria for selecting suitable measurement methods for determining the measured quantities in accordance with the StandAG.

$\checkmark$ Factors influencing the criteria for selection of suitable measurement densities and measurement intervals.

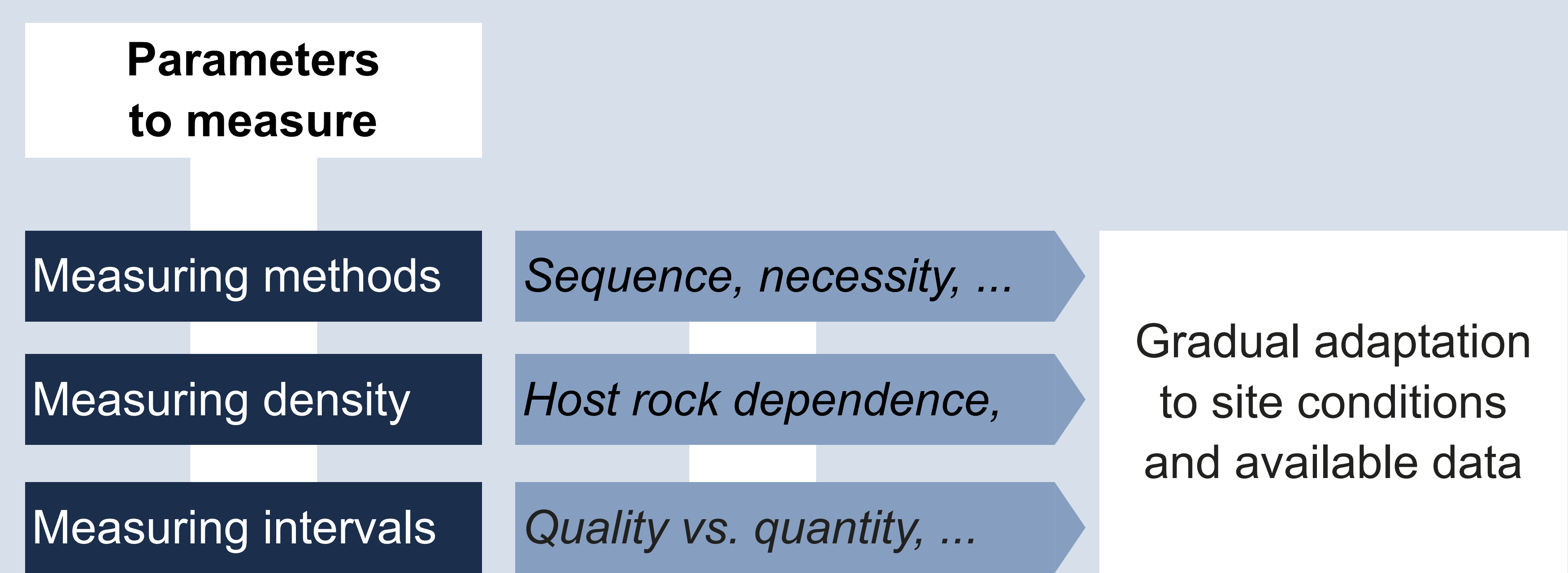

Orientation framework:

Evaluation of proposals for the surface exploration of site regions
Authors
K. Haneke, M.Sc. ${ }^{1}$
Dr.-Ing. J. B. Pateiro Fernández
Dr.-Ing. C. Pieper ${ }^{2}$
Dr.-Ing. B. Starke
Dr. A. Schuck ${ }^{3}$
Dr. A. Schuck

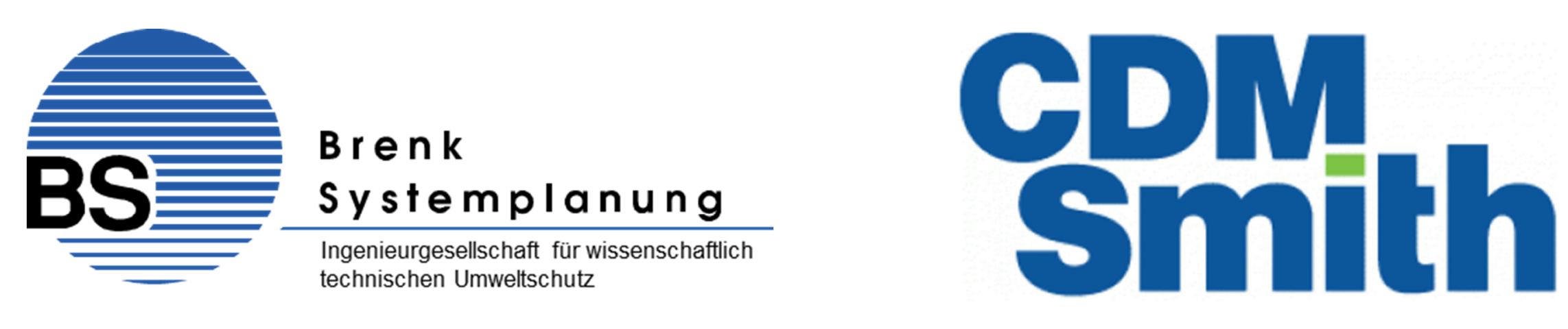
I Federal Office for the Safety of
Nuclear Waste Managemen
on behalf of the Federal Office
for the Safety of Nuclear Waste Management 